Professor Donald's experiences also give us valuable insignts into a patient's morale-his own improved with the removal of each successive piece of tubing as he became less and less like a porcupine. Inability to communicate (owing to the endotrachial tube) he found vastly frustrating. Rapport with other patients provided a strong fellow feeling-there is a lot to be said for the companionship of multi-bedded units. Throughout the whole account runs the thread of optimism and courage with which he faced this third experience of cardiac surgery, and, in passing his reactions on to the rest of doctors, Professor Donald has done a great service to his fellow patients.

1 Lancet, 1969, 2, 1129.

2 Donald, I, Scottish Medical fournal, 1976, 21, 49.

\section{Staffing in the hospital service}

At present one-third of the 30000 hospital medical staff and one-fifth of the 20000 general practitioner principals in the NHS were born overseas; in all there are nearly 20000 overseas doctors fully or provisionally registered in Britain. For years now the valuable contribution made by these doctors to the NHS has been acknowledged by leaders of the medical profession and by politicians, but since publication of the Merrison report ${ }^{1}$ and the introduction of TRAB tests for new medical immigrants complaints of exploitation and discrimination have been heard more and more often. Last week the Community Relations Commission published proposals, ${ }^{2}$ which it is submitting to the Royal Commission on the NHS, for changes in the registration and training of overseas doctors. Its report spelt out the grievances that trouble many such doctors, particularly those who have settled in Britain as permanent citizens, though, inexplicably, it ignored the help given to so many of them over the years by the BMA Commonwealth Bureau.

Few other aspects of medicine have been the subject of so much cant and double talk as the treatment of overseas doctors. For the whole of its 28 year existence the NHS hospital service has been based on a grossly distorted staffing pyramid with many thousands more hospital junior staff employed in socalled training posts than could possibly be required to fill consultant vacancies due to death or retirement. The disparity has been solved, year by year, partly by the overall growth of the hospital service (medical inflation); partly by emigration of well-trained registrars and senior registrars; but largely by an import-export business of doctors from overseas who were prepared to work a few years as pairs of hands while acquiring clinical experience and (they hoped) postgraduate diplomas and degrees. So long as nearly 2000 new doctors arrived each year from abroad and much the same number left, the pyramid could maintain its shape; but circumstances have changed. Around the world medical migration has slowed enormously in the last few years, so that fewer doctors are coming here. In consequence the present system is showing signs of collapse -in particular the growing numbers of unfilled vacancies in the less popular hospital specialties.

The arithmetical impossibility of balancing the numbers of career posts with the numbers of doctors in training is no sudden discovery, but successive attempts to introduce a more rational system have foundered for lack of any unanimity of medical opinion. Both consultants, who have no wish to see the quality of their work diluted by an increase in their numbers, and junior staff have opposed the introduction of a permanent subconsultant grade, and BMA policy has insisted that all junior posts should be proper training posts. No one, it seems, has been prepared to advocate solving the equation by creating many more permanent part-time appointments, and the spectre of the former senior hospital medical officers has served as an awful warning of the hazards of having more than one full-time career grade. The nature of the hospital practitioner grade, brought into being last year after prolonged negotiation, shows how these fears have operated. The grade was designed to bring GPs into hospitals, and by limiting entry to principals in general practice and limiting them to five sessions a week the regulations have excluded many of the clinical assistants currently doing sessional work in hospitals. Not surprisingly, these clinical assistants-many of whom have invaluable practical experience-resent the large differential between their pay scale and that of hospital practitioners (whose pay, understandably, is linked to that of GPs). Rapid growth in numbers of hospital practitioners seems unlikely, however, for several reasons: one factor may be the disturbance caused to group practice arrangements which sometimes seems to create frictions that outweigh the other advantages for the individual concerned.

A more effective long-term solution to the staffing dilemma must be found, and one obvious possibility is the introduction of a grade closer to the European specialist, ${ }^{3}$ with many more specialists doing the service work of the NHS and fewer doctors in the training grades. As vocational training for general practice and the programmes within each hospital specialty become more closely controlled, hospital junior posts will inevitably become clearly divided into those that provide useful training and those that do not, and the unsatisfactory SHO and registrar jobs should gradually disappear. A steady reduction in the total number of junior hospital posts should combine with an increase in the output of graduates from our medical schools to make it unnecessary for more than a handful of doctors to be imported to balance the equations-that is, given that emigration of British doctors does not increase any further.

Where would such a solution leave overseas doctors? Some would still come here for postgraduate training-on exchange scholarships and as participants in formal training programmes. The flow of independent medical immigrants would be much reduced, and some sort of work permit system might prove necessary. This change should bring advantages for the overseas doctors already here, for such prejudice as does exist against them has largely been fuelled by new arrivals' difficulties with the English language and with our medical system.

Indeed, if this becomes the future pattern doctors born overseas may be ill-advised to continue to press for representation as a group on NHS committees, negotiating teams, and other medical bodies. Such representation will tend to perpetuate their isolation as a minority group. If they are to be integrated into the medical community here-as they should be-then they should join the various societies and medicopolitical associations as equal members with British-born graduates - and already within the BMA there are signs that this is what is happening.

${ }^{1}$ Report of the Committee of Inquiry into the Regulation of the Medical Profession (chairman Dr A W Merrison). London, HMSO, 1975.

2 Reference and Community Services, Doctors from Overseas. A Case for Consultation. London, Community Relations Commission, 1976.

${ }^{3}$ British Medical fournal, 1976, 1, 546. 